\title{
Levels of rare earth elements in hair from a group of young Spanish adults (aged 20-24 years)
}

Antonio Peña-Fernández ${ }^{1,2}$, Santiago Angulo³, María del Carmen Lobo-Bedmar MC ${ }^{4}$

${ }^{1}$ School of Allied Health Sciences, De Montfort University, Leicester, LE1 9BH, UK.

${ }^{2}$ Universidad de Alcalá, Departamento de Ciencias Biomédicas, Crta. Madrid-Barcelona Km, 33.6, 28871 Alcalá de Henares, Madrid, Spain.

${ }^{3}$ Facultad de Farmacia, Universidad San Pablo CEU, Urbanización Montepríncipe, Boadilla del Monte, Madrid, Spain.

${ }^{4}$ Departamento de Investigación Agroambiental. IMIDRA. Finca el Encín, Crta. Madrid-Barcelona Km, 38.2, 28800 Alcalá de Henares, Madrid, Spain.

The rapid agricultural, medical and industrial development is occurring on a global scale and bringing with emerging environmental threats for humans. Contamination by rare earth elements (REE) has emerged as a public health concern due to their numerous applications in the current industry. However, little is known about their toxicological effects despite they can accumulate in different organs including brain and bone. To determine the exposure to these contaminants in a young Spanish population, scalp hair samples were collected in 37 young adults (20 to 24 years-old; 28 female and 9 male) from different towns in the Community of Madrid (Spain). Despite being controversial, human hair could be an appropriate tool to determine environmental exposure to inorganic metal contaminants and to estimate the chemical burden in the individual. Lanthanum ( $\mathrm{La}$ ), cerium (Ce), praseodymium ( $\mathrm{Pr}$ ), erbium ( $\mathrm{Er}$ ) and gadolinium (Gd) were analysed in these samples by ICP-MS following appropriate methodologies. The limits of detection were (in $\mathrm{ng} / \mathrm{g}$ ): La (1.87), Ce (4.29), $\operatorname{Pr}$ (0.47), $\operatorname{Er}(0.06)$ and $\mathrm{Gd}(0.24 \mathrm{ng} / \mathrm{g})$. Gd was detected only in one of the monitored samples $(2.66 \mathrm{ng} / \mathrm{g}$ ). The concentrations were as follow (median and percentiles are provided in $\mathrm{ng} / \mathrm{g}$ ): La 5.30 (4.22, 7.13), Ce 11.18 (8.97, 15.45), $\operatorname{Pr} 1.28(1.04,1.72)$ and $\operatorname{Er} 0.19(0.14,0.28)$. In general, the presence of these metals in the Spanish group's hair monitored were lower than those reported in environmentally exposed groups, which may indicate that the studied group would have a low exposure to REE. None of these elements showed influence due to sex, although slightly higher levels were observed for La (5.57 vs. 5.17 $\mathrm{ng} / \mathrm{g}), \operatorname{Pr}(1.40$ vs. $1.27 \mathrm{ng} / \mathrm{g}), \mathrm{Nd}(2.48$ vs. $2.29 \mathrm{ng} / \mathrm{g})$ and $\operatorname{Er}(0.21 \mathrm{vs.} 0.19 \mathrm{ng} / \mathrm{g})$ in men's hair and in women's hair for Ce (11.58 vs $10.30 \mathrm{ng} / \mathrm{g}$ ). Despite is unclear, our results would be in agreement with those studies that have suggested that men may be more sensitive to REE than women.

Keywords: Rare earth metals, human hair, monitoring, Spanish young adults. 